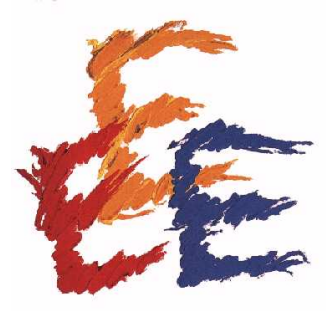

Fondazione Eni Enrico Mattei

\title{
The Use of Common Property Resources: A Dynamic Model
}

\author{
Michele Moretto* and Paolo Rosato**
}

NOTA DI LAVORO 13.2002

\section{JANUARY 2002}

NRM - Natural Resources Management

* Department of Economics, University of Padua

**Department of Civil Engineering, University of Trieste

This paper can be downloaded without charge at:

The Fondazione Eni Enrico Mattei Note di Lavoro Series Index: http://www.feem.it/web/activ/_activ.html

Social Science Research Network Electronic Paper Collection: http://papers.ssrn.com/abstract_id=304320

Fondazione Eni Enrico Mattei

Corso Magenta, 63, 20123 Milano, tel. +39/02/52036934 - fax +39/02/52036946

E-mail: letter@feem.it

C.F. 97080600154 


\section{SUMMARY}

The government of common agricultural and forestry land is a topic that is currently enjoying a revival of interest. Many local communities have shown the ability to pursue sustainable use of natural resources thanks to their self-governed authorities. In this context the relationship between public and private interest which is established in use of the resource is a fairly controversial. The paper proposes a dynamic model to analyse the behaviour of a user of a common property resource in a "real option" framework, where the value of the right to use the resource is affected by: 1) uncertainty on the future amount of the resource; 2) entry and exit costs and 3) the number of users competitors.

Key words: Common property resources, option value, uncertainty 


\section{CONTENTS}

1. Introduction 2

2. Common property goods or pure public 4 goods?

3. A model for the use of common property 7 resources

4. Some comparative statics 15

5. Conclusions 17

References $\quad 21$ 


\section{Introduction}

The collective use of natural resources, first and foremost agricultural and forestry land, has been an important factor in the social and economic evolution of many rural communities. Local historiography is, in fact, dotted with episodes directly or indirectly linked to the exercise of collective rights over private land or the government of common property land. The mixture of public and private rights in the use of land has very ancient origins (Forni, 1972; Sereni, 1955) and is probably linked to the practical impossibility of enforcing property rights over all the benefits produced by the land and/or the expediency of tailoring the procedures for use of the specific benefit to its characteristics (economies of scale, organisation of work, aversion to risk $)^{1}$.

From their origins to the present day, collective uses have undergone considerable changes, all directed to a progressive reduction of their role, in favour of substantial privatisation (Merlo, 1995). There are various reasons for this trend: a) the establishment of central national authority over the local power of the communities; b) the pressure exerted by the great landed property over public lands ${ }^{2}$; c) the expediency of removing impediments preventing rational cultivation of the land (Acerbo, 1924) ${ }^{3}$.

The historical vicissitudes of common property can be interpreted also by analysing the relationship between evolution of the productivity of the land and the level of social and economic development:

- where productivity was subject to rapid appropriable improvements, in general a gradual privatisation of common property has occurred, as for example in the common property lands of the northern plain of Italy;

- where productivity is modest (forestry land, marginal grazing land) and social and economic development is good, common property has been maintained and is undergoing transformation into institutions with mainly social and environmental objectives: Communities of the Eastern Alps;

- where productivity is modest and social and economic development is behind, common property has been maintained for mainly economic purposes but it has not produced strong enough institutions to cope with the change of roles which it will sooner or later be called upon to undertake: common lands of the marginal areas.

\footnotetext{
${ }^{1}$ For example, aversion to risk can encourage collective forms of use of a given resource with uncertain availability. In this way the risk is shared by the entire community, reducing the possibility of one of the members finding himself in an untenable situation.

${ }^{2}$ This happened mainly in the case of public property land. For example in the Veneto countryside in the seventeenth century many of the rights to the use of common land for grazing, collecting straw and leaves for animal bedding and gathering firewood were alienated by the Venetian Republic under the pressure of the requirements of war against the Turks and the emerging landed aristocracy (Pitteri, 1984).

${ }^{3}$ In this regard see law no. 1766 of $16 \mathrm{th}$ June 1927 on the reorganisation of common property and subsequent additions.
} 
In some rural areas, therefore, where the tradition of local government was more firmly rooted (alpine areas) or where the difficulties of private economic exploitation were greater (marginal grazing lands), forms of collective land use have survived. The reasons for this phenomenon are many and difficult to classify as various environmental, economic and political factors are involved, the analysis of which goes beyond the scope of the paper.

These situations, however, appear to be united by the need to reorganise action according to new environmental objectives. Analysis of the relationship which these communities have succeeded in establishing with the natural resources governed therefore constitutes an element of considerable topical interest. In fact, contrarily to the forecasts of the theoretical models on the use of common property goods (Hardin, 1968; Ostrom, 1999) there are significant examples of how some of them have succeeded in establishing a balanced relationship with the surrounding environment, to the extent that use of the resources can be defined as "sustainable" ${ }^{\text {. }}$

Analysis of the success of these institutions in the government of common natural resources cannot disregard the relationship between private use and public interest. In fact, pursuit of the objectives of the communities in government of the resources requires the adhesion of the subjects involved. Often the social benefits produced by common government are linked to productive use of the resources by private individuals. In this case private use is combined with a positive external factor ${ }^{5}$ : public benefit.

This study proposes a model which, with reference to a "typical" holder of a collective resource use right, permits assessment of the expediency of using or not using it according to his current state (user or non-user). As the decision shares the characteristics of the majority of investment decisions, i.e. it is a choice which always has a certain irreversible component, it is taken in the presence of uncertainty as to the extent of the future benefits and it is a decision that can, to a certain degree, be postponed, it is reasonable to assume that the best choice must satisfy slightly more restrictive conditions on expected utility than those suggested by the usual present net value. Uncertainty in the availability

\footnotetext{
${ }^{4}$ The definition of sustainability in the use of resources and in development is highly controversial (Howarth, 1997). However, if we assume as reasonable the definition given by the Brundtland commission "sustainable development is development that satisfies the needs of the present without compromising the needs of the future" (WCED, 1987) and the analytical consequences in terms of "non-decreasing utility" in the long term (Pearce and Turner, 1990), development of the relationship between local communities and natural resources that has been established in many of these institutions can undoubtedly be defined as" sustainable". On the role of collective properties in the government of natural resources, see also Franceschetti (1999).

${ }^{5}$ The definition of externality is fairly elusive. In this context, an enlightening definition is the one proposed by Baumol and Oates (1988, p.17-18) who subordinate the presence of externalities to two conditions "1). . . . whenever some individual's (say A's) utility or production relationship include real (that is non monetary) variables, whose values are chosen by others (persons, corporations, governments) without particular attention to the effects on A's welfare; 2) The decision maker, whose activity affects others' utility levels or enters their production functions, does not receive (pay) in compensation for this activity an amount equal in value to the resulting benefits (or costs) to others".
} 
of natural resources implies that there can be future conditions that may vary present expediency. The irreversibility of certain costs, both entry and exit, means that, if the user opts for a certain decision, he will not be able to recover the related cost. Finally, the expediency of waiting to decide enables him to acquire more information and therefore reduce the probability of regretting the choice made. Having said this, the choice the user (actual or potential) has to make can be compared to a "real option" or a right, but not obligation, to make or divest himself at any time of an investment at pre-set conditions and, therefore, the uncertainty as to the future benefits brings out a value linked to the expediency of postponing the choice ${ }^{6}$.

The model was used to test the entry and exit conditions in use of the resource in the presence of certain factors such as uncertainty and investment/disinvestment costs. The study of these conditions holds a certain interest as the effectiveness of the management and the economic and social efficiency of these institutions is closely linked to collective participation in use of the shared resource. Excessive use or, more often, abandonment can lead to profound modifications in the institutional set-up and the ability to pursue the set purposes.

\section{Common property goods or pure public goods?}

Before illustrating the model that represents the behaviour of the user of the common property resource it is useful to correctly focus on the use of the common resource from the economic point of view in order to clearly define the boundary conditions. From this point of view the reference to the theory of public goods which usually classifies economic goods according to rivalry and excludability in consumption is immediate (see table 1$)^{7}$.

Table 1 - A general classification of economic goods

\footnotetext{
${ }^{6}$ In other words the user, actual or potential, clearly perceives the benefits deriving from the possibility of postponing the decision (value of the option) in the absence of reliable information on the future evolution of the usable resource (Freeman, 1984) and in the presence of non-reversible costs (Conrad, 1999). A recent manual by Dixit and Pindyck (1994) provides a thorough survey of this approach applied to various economic questions.

${ }^{7}$ The classification does not take account of the legal status (public or private) of the owner and is based exclusively on the way in which the goods are used. There is rivalry in consumption when the use of goods by an individual is not compatible with that of other subjects. The same amount of goods cannot be used by several subjects and the increase in users necessarily involves an increase in the availability of the goods. On the contrary, "nonrival" goods and services are characterised by the fact that their utilisation by an individual is compatible with consumption by one or more individuals. An increase in the number of users does not necessarily determine an increase in the quantity of the goods utilised. On the other hand, excludability in consumption exists when it is possible for the holder of certain goods to exclude, and therefore select, the users from the benefits produced by the goods. This depends on the concrete possibility of asserting property rights over the goods produced or owned (Brosio, 1986; Ostrom et al., 1994).
} 


\begin{tabular}{|l|l|l|}
\hline Excludability & Rivalry & Type of goods \\
\hline Difficult & Modest & Pure public goods \\
\cline { 2 - 3 } & High & Common-pool resources \\
\hline \multirow{2}{*}{ Easy } & Modest & Toll goods \\
\cline { 2 - 3 } & High & Private goods \\
\hline
\end{tabular}

Examination of the table shows that common resources fall into the category of common-pool resources. This classification, however, is not of great use in identifying the reasons for the success recorded by some communities in conserving common resources: there are considerably more complex questions than those that can be described via the above pattern.

It could be useful to study excludability in further detail. The latter, in fact, could be assessed with respect to two distinct points of view: the user and the quantities used (see table 2).

Table 2 - A classification of rival consumption goods according to the type of excludability

\begin{tabular}{|l|l|l|}
\hline Excludability & \\
\hline Quantities used & User & Type of goods \\
\hline Easy & Easy & Private goods \\
\hline Difficult & Difficult & Common-pool resources \\
\hline & Easy & Common property goods \\
\hline
\end{tabular}

It is obvious that if the excludability is realisable for each specific unit of resource, it is implicitly realisable also for the user: this is the case of private goods. On the contrary if it is difficult to monitor the quantities used and the users, we have the case of the so-called "commons" and the predictable "tragedies" well described by Hardin (1968).

Finally, there are cases in which it is possible to perform an effective control on the users whereas control of the quantities actually used is much more uncertain. This is the case of property in small communities where the persons with the right to use of the resource are easy to identify but it is much more difficult to know the amount of resource actually collected due to the laboriousness of the related controls and uncertainty as to the amount of resource available at the time of collection ${ }^{8}$. The uncertainty on the quantities used by each person with the right to use of the resource could be mitigated by knowledge of the technology available or admitted for use of the common resource. The condition for the constitution of institutions for the government of common resources therefore appears to be the possibility of exercising sufficient exclusion from use of those who do not have the right to said use. In fact, it would be pointless for

\footnotetext{
${ }^{8}$ For example, it is very difficult to know the exact amount of mushrooms, fish or game available for the user in a certain context due to the variability in the environmental and meteo-climatic conditions.
} 
a community to create rules for the use of a resource if external subjects can access it undisturbed.

The possibility of circumscribing the community of users is not sufficient, however, to explain the success of some communities in the management of environmental resources. Various authors have underlined that the reasons for this should be first of all sought in ethical and cultural factors and, definitively, in the value attributed by individuals to membership of communities with wellestablished traditions. The considerable difficulties in reconstructing common government of resources where it has been abandoned in the past (Edwards, 1998; Merlo, 1995) support this theory ${ }^{9}$.

The question was dealt with in depth by Elinor Ostrom $(1996,1999)$ by studying communities that boast a consolidated tradition in the government of common resources. The reason underlying the success of the communities examined appears to lie in the ability to adopt appropriate rules for use of the common resource and in observance of the same. This ability can, at least partially, be traced back to the characteristics of the resource and the users.

\section{- Characteristics of the resource (CR):}

1. the establishment of common rules must be able to substantially improve the benefits produced by the resource;

2. it must be possible to easily monitor the resource and at low cost;

3. it must be possible to make sufficiently reliable forecasts on the future trend of the benefits deriving from the resource;

4. the resource must be of limited dimensions with respect to the technology available in order to permit the users an accurate knowledge of its borders and characteristics.

\section{- Characteristics of the users (CU):}

1. the well-being of the users must depend largely on the resource;

2. the users must have a good knowledge of how the resource is made available and the implications of their actions;

3. the users must discount the future benefits of the resource at a relatively low rate;

4. the users constitute a close-knit and loyal community;

5. the users must have sufficient decision-making independence in establishing the rules for use of the resource;

\footnotetext{
${ }^{9}$ In this regard it is helpful to remember the regional law no. 26 dated 19.8.96 "Reorganisation of rules" in which the Veneto Regional Authorities explicitly recognised the role of common property in safeguarding the environment and local development and laid down the rules for promoting their reconstitution.
} 
6. the users must have minimal organisational and managerial experience.

The complex of characteristics well suits the communities which over the centuries have succeeded in establishing shared and respected rules. It is interesting to note that, as a whole, the above-mentioned requirements contribute to defining the typical macrocriteria of expediency (CR1, CR2, CR3, CF1, CF3) and feasibility (CR4, CF2, CF4, CF5, CF6). Therefore, the conditions required for the realisation of common management of resources are fairly restrictive: in fact, they constitute the exception and not the rule.

Alongside the characteristics of the resource and the users of it, the requirements for the institution governing use of the resource to ensure its perpetuation have also been identified.

\section{- Characteristics of the institution (CI):}

1. the rights of the users must be clearly defined (excludability of users) and there must be a precise identification of the resource (CR4); ̀̀

2. the rules for use must be coherent with the local socio-economic conditions;

3. all the users must be able to participate in definition of the rules (CR5);

4. the controls must be effective (CF4);

5. the sanctions must be gradual and effective;

6. the solution of conflicts must be rapid and efficient;

7. the community holding the resource must have the right and the ability to organise itself (CF5, CF6).

The set of rules illustrated above constitutes the foundation of the so-called "institutional" approach to the government of common property resources and forms the framework within which analysis of user behaviour is performed with the tools typical of the game theory. The use of said analysis tools presupposes that it is possible to assess the advantages and disadvantages connected with the choices that each user (player) can make. In other words, that a function able to represent the value of the benefit obtainable in the different situations is available. The following paragraph presents a model for assessment of the benefit of the user in order to represent the dynamics of his choices.

\section{A model for the use of common property re- sources}

In the previous paragraph the main economic characteristics of common property resources have been described, attempting to identify the distinguishing elements with respect to open access goods. 
The focus now moves from examination of the system characteristics to analysis of individual user behaviour. The analysis was performed presupposing that there is a certain co-operation (see also CF4, CI3, CI4) between the users and respect for the common rules. Under this assumption, modelling of the interactions between the competitors normally achieved by means of the classic tool of non-cooperative games (Ostrom et al., 1994; p. 51-73) takes second place with respect to analysis of the expediency of the individual user and the main factors conditioning the benefit ${ }^{10}$.

Generally speaking, the expediency of using a common resource is assessed by pondering the costs and benfits deriving from use. Furthermore, since the assessment can be made at any time, it is not sufficient for the current benefits to exceed current expenses; it is also necessary for the net benefit to be greater than the net benefit obtainable by exercising the right of use at any future time. The latter requirement is very important when using resources of biological origin, the utility flow of which varies due to natural causes such as seasonal or annual variations or due to anthropic causes such as environmental renewal and draw-off by other activities.

Let's consider a potential user of a resource who assesses, at a given time, the expediency of using it and who has to submit to the following boundary conditions, which summarise and integrate those illustrated in the previous paragraph.

1. the right cannot be bought or sold but is acquired with the occurrence of particular conditions (residence, inheritance, etc.);

2. the holder of the right is free to use it or not and renunciation of use of the right does not involve any compensation;

3. the decision to exercise the right always generates a non-recoverable outlay (irreversible investments);

4. the decision to cease exercise of the right of use can generate non-recoverable exit costs;

5. the decision to exercise the right, interrupt or resume use can be taken at any time;

6. the decision to exercise the right involves the production of a negative external factor affecting the other actual users and due to the resource subtracted by the user;

7. the user respects the rules established by the community for use of the resource.

Assuming the previous boundary conditions, construction of the model presupposes the definition of a benefit function. The latter depends, given that the

\footnotetext{
${ }^{10}$ The interactions between users is beyond the scope of the paper as well as the type of equilibrium that users may form at aggregate level.
} 
market prices and technology available or permitted are known, on the quantity of resource that is expected to be obtained. Therefore, the instantaneous net benefit expected by the user of the resource is given by the following function $B\left(x_{t} ; n_{t}\right)$, with $B_{x}>0$ and $B_{x x} \leq 0$, where $x_{t}$ is the stock of resource at time $t$ and $n_{t}$ indicates the number of rival users drawing on the same stock at the same time. The number of potential rival users can vary between 0 and $n$ (maximum number of persons with the right to use the resource). $n$ can be considered constant for the rest of the analysis, since the number of persons with the right to use of the resource changes very slowly ${ }^{11}$.

The number of rival users is inserted in the benefit function as it is assumed that the instantaneous quantity of resource available for each user is negatively correlated with their number due to a competition effect ${ }^{12}$. Therefore, an increase in real rivals produces a reduction in benefit, i.e. $B_{n}<0$.

The amount of the resource considered is measured by a variable $x_{t}$ which, it is assumed, satisfies the following stochastic differential equation ${ }^{13}$ :

$$
\begin{aligned}
d x_{t} & =\mu\left(x_{t} ; n_{t}\right) d t+\sigma x_{t} d W_{t}, \text { with } x_{0}=x, \sigma>0 . \\
\mu\left(x_{t} ; n_{t}\right) & =\gamma\left(x_{t}\right) x_{t}-h\left(x_{t}, n_{t}\right) n_{t}
\end{aligned}
$$

In the equation (1) $\gamma\left(x_{t}\right)$ represents the expected natural growth rate of the stock and is decreasing with respect to the amount of the stock itself $x_{t}{ }^{14}$; $h\left(x_{t}, n_{t}\right) n_{t}$ is the expected individual collection rate multiplied by the number of users present at time $t$ and represents the reduction of the stock produced by use on the part of the competitors. This reduction is generally positively linked to the consistency of the stocks. The expected individual collection rate is positively correlated with the consistency of the stock and negatively with the number of rival users ${ }^{15}$.

The model also incorporates the possibility of some chance factors, such as meteorological and climatic trends, affecting the stock and the growth rate of the biomass. The term $\sigma x_{t}$ is the measure of the variability and $d W_{t}$ is the differential of a Brownian motion with mean $E\left(d W_{t}\right)=0$ and variance

\footnotetext{
${ }^{11}$ In fact, years of residence are usually necessary to be admitted to use of the common resource.

${ }^{12}$ It should be noted that the problem faced by a single user who shares the resource with others differs from the one of the policy-maker who considers the aggregate benefit of all the users. In this context the user, if rational, will include an assessment of the stock in his benefit function and this assessment will vary inversely with the number of rivals present (Arnason, 1990).

${ }^{13}$ For an introduction to differential stochastic equations and Brownian motions, see Cox and Miller (1965), and Harrison (1985).

${ }^{14}$ The models most widely used to optimise the use of renewable resources incorporate processes of autolimitation of the growth rate as the stock grows (Clark, 1990).

${ }^{15}$ This assumption is in line with the classic approach to modelling of the use of renewable resources where the effort spent in collection $(E)$, understood as the aggregate of capital, energy and work employed in a certain interval of time (Schaefer, 1954) necessary for the collection of a certain quantity $(h)$ of resource, is inversely proportional to the consistency of the stock $(x)$.
} 
$E\left[\left(d W_{t}\right)^{2}\right]=d t^{16}$.

A simple reduced form for $\mu\left(x_{t} ; n_{t}\right)$ could be identified by the following expression: $\mu\left(x_{t} ; n_{t}\right)=\mu\left(n_{t}\right) x_{t}$, with $\mu^{\prime}\left(n_{t}\right) \leq 0$ to take account of the fact that an increase in competitors reduces the growth rate of the stock of resource available ${ }^{17}$. In this way, $x_{t}$ becomes a geometric Brownian motion:

$$
d x_{t}=\mu\left(n_{t}\right) x_{t} d t+\sigma x_{t} d W_{t}, \text { with } x_{0}=x, \sigma>0 .
$$

which allows us to obtain a closed solution for the value of the right to use of the resource.

\subsection{The value of the right to use of the collective resource}

The right of use consists in the faculty to draw on a certain common resource for a certain period, in the places prescribed and according to established procedures. In other words it can be considered as an asset that provides an instantaneous benefit $B\left(x_{t} ; n_{t}\right)$ which depends on the level assumed by the stock of resource and the number of users. We assume, without losing out in generality, that $n_{t}$ is constant and equal to the maximum number of users $n$. We also assume for $B$ a functional form of the type:

$$
B\left(x_{t} ; n\right)=B(n) x_{t}^{\xi}, \text { with } \quad 0<\xi<1
$$

It is now possible to identify the amount of the net benefit produced by the common resource at time $t$. This benefit will be different depending on whether the holder of the right is exercising it or not. For an individual who is actively using the resource, the net benefit is expressed, at time $t$, by the function:

$$
\pi\left(x_{t} ; n\right)=B(n) x_{t}^{\xi}-c
$$

The fixed costs we consider here are, as standard in the literature, flow fixed costs of production: that is, we assume that the user begins the first period

\footnotetext{
${ }^{16}$ The specification of the variability adopted in the (1) could be enriched, without in any way altering the results obtainable, with the representation of sudden variations in the stock of resource caused by exceptional external events such as pollution, fire, poaching etc. In this case the (1) becomes:
}

$$
d x_{t}=\mu\left(x_{t} ; n_{t}\right) d t+\sigma x_{t} d W_{t}+x_{t} d Q_{t},
$$

where $d Q_{t}$ is the variation of a Poisson process, independent of $W_{t}$, with mean arrival time $\lambda$. The process $d Q_{t}$ then has the following probability distribution:

$$
d Q_{t}= \begin{cases}\phi & \text { with probability } \lambda d t \\ 0 & \text { with probability } 1-\lambda d t\end{cases}
$$

In this regard see Moretto and Rosato (2000).

${ }^{17}$ See Moretto and Rosato (2000) as to abtain this form of the growth rate of the stock. 
endowed with an unit of capital the operation of which entalils a flow cost $c$ per unit of time. If, on the contrary, the holder of the right does not exercise it, we will have $\pi\left(x_{t} ; n\right)=0$. Yet, the holder of the right sustains a sunk cost $k>0$ whenever $\mathrm{s} /$ he wishes to make this right operative ${ }^{18}$ and an exit cost equal to $l \geq 0$ if $\mathrm{s} /$ he renounces use of the resource ${ }^{19}$.

Since, from (2), the actual user is aware that the stock of resource available can increase and diminish with a positive probability, it is evident that s/he can continue using the resource even in particularly adverse conditions in the hope of avoiding the exit cost $l$ and/or any re-entry cost $k$. In the same way, the potential user will decide to activate the process of utilisation of the resource only if the expected benefit is considerably higher than the entry cost $k$, in order to take account of the possibility of it worsening following a negative fluctuation of $x_{t}$.

As highlighted by Dixit (1989) and Moretto (1996), the decision to keep or exercise the two options available to the user must be taken with respect to two thresholds $x_{L}$ and $x_{H}$, with $x_{L}<x_{H}$, in the resource stock $x_{t}$. An actual user will find it expedient to continue in his/her activity as long as the stock of resource remains above the minimum level defined by $x_{L}$, but will suspend use as soon as $x_{t}$ drops below $x_{L}$. On the contrary, an individual who has to decide whether to exercise his/her right will activate utilisation only if the stock rises above the threshold $x_{H}$. As long as $x_{t}$ does not exceed this threshold, his/her optimal strategy will be to wait, without exercising the option (right) of use the resource.

Assuming that there is homogeneity among users and that each one decides whether to activate or not utilisation of the resource in order to maximise his/her discounted value of future expected net benefits, it is possible evaluate the right to use of the common resource in the two possible situations:

- actual use;

- potential use.

Defining $W_{1}(x)$ as the value of the right to use of the collective resource by an individual who is actually using the resource, we get:

$$
W_{1}(x)=E\left\{\int_{0}^{T_{L}} e^{-\rho t}\left[B(n) x_{t}^{\xi}-c\right] d t \mid x_{0}=x\right\}+
$$

\footnotetext{
${ }^{18}$ It should be noted that if the holder of the right decides to resume use of the resource $\mathrm{s} /$ he will have a new outlay equal to $k$, as it is inherent in the assumptions (Dixit, 1989).

${ }^{19}$ As pointed out by Tirole (1988, p.307), fixed costs are indipendent of the scale of production and are locked in (sunk) for the short lenght of time that defines the production period. For natural resources extraction, $c$ may reperesent the amonut of money spent by the user to reach the resources site, while $k$ could be referred to the capital, not fully reconvertible, necessary for the use of the resource. The expense $l$, on the other hand, could be referred to restoration of the initial conditions of the resource.
} 


$$
+E\left\{e^{-\rho T_{L}}\left[W_{0}\left(x_{L}\right)-l\right] \mid x_{0}=x\right\}, \quad \text { for all } x \in\left(x_{L}, \infty\right)
$$

where $\rho$ is the discount rate and $W_{0}\left(x_{L}\right)$ represents the value of the right to use the resource by an individual who is not actively using it. This "potential" value is calculated at time $T_{L}=\inf \left(t \geq 0 \mid x_{t}<x_{L}\right)$ when the user will refrain from exercising his/her right, and $x_{L}$ is the threshold that has induced him/her to refrain from use.

If, on the other hand, an individual is in the position of being a potential user, his/her optimal strategy will be to implement utilisation only if the stock of resource reaches the threshold level $x_{H}$. Since s/he receives no benefit from the resource while s/he is waiting, we get:

$$
W_{0}(x)=E\left\{e^{-\rho T_{H}}\left[W_{1}\left(x_{H}\right)-k\right] \mid x_{0}=x\right\}, \quad \text { for all the } x \in\left(0, x_{H}\right),
$$

where $T_{H}=\inf \left(t \geq 0 \mid x_{t} \geq x_{H}\right)$ indicates the moment, and $x_{H}$ the threshold, at which it will become expedient to activate the utilisation process.

\subsection{The user's optimal strategy}

The model described in the previous paragraph enables us to identify the optimal strategy of the user, actual or potential, with regard to the common resource. This strategy takes the form of the choice between the options described in table 3 .

Table 3 - The options in use of the common resource

\begin{tabular}{|l|l|l|}
\hline Initial situation & Possible options & State of the resource \\
\hline Uses & Continues to use & $x_{t} \geq x_{L}$ \\
\cline { 2 - 3 } & Stops using & $x_{t}<x_{L}$ \\
\hline \multirow{2}{*}{ Does not use } & Continues not to use & $x_{t} \leq x_{H}$ \\
\cline { 2 - 3 } & Begins using & $x_{t}>x_{H}$ \\
\hline
\end{tabular}

The optimal strategy is identified by solving a dynamic programming problem. $>$ From equations (5) and (6) the solution for $W_{1}$ and $W_{0}$ must satisfy the following conditions (Dixit, 1989; Moretto 1996):

$$
\begin{array}{cc}
\Gamma W_{1}(x)=-\left[B(n) x^{\xi}-c\right], & \text { for } x \in\left(x_{L}, \infty\right) \\
\Gamma W_{0}(x)=0, \quad \text { for } x \in\left(0, x_{H}\right)
\end{array}
$$

where $\Gamma$ indicates the differential operator:

$$
\Gamma=-\rho+\hat{\mu} x \frac{\partial}{\partial x}+\frac{1}{2} \hat{\sigma}^{2} x^{2} \frac{\partial^{2}}{\partial x^{2}}, \text { with } \hat{\mu} \equiv \xi \mu(n)-\frac{1}{2} \xi(\xi-1) \sigma^{2} \text { and } \hat{\sigma} \equiv \xi \sigma \text {. }
$$


The operating constraints are:

$$
\begin{gathered}
W_{1}\left(x_{L}\right)=W_{0}\left(x_{L}\right)-l \\
W_{0}\left(x_{H}\right)=W_{1}\left(x_{H}\right)-k \\
W_{1}^{\prime}\left(x_{L}\right)=W_{0}^{\prime}\left(x_{L}\right) \\
W_{0}^{\prime}\left(x_{H}\right)=W_{1}^{\prime}\left(x_{H}\right)
\end{gathered}
$$

The four equations (9)-(12) indicate the usual conditions of value matching and smooth pasting for identification of the optimal strategy. The value matchings (9) and (10) require the indifference of the user at the time of switching from the status of actual user to that of potential user and vice versa. The smooth pastings determine optimality for the threshold values $x_{L}$ and $x_{H}$.

Together with the equations (9)-(12), the solution of the differential equations $(7)$ and (8) requires certain boundary conditions:

$$
\lim _{x \rightarrow \infty}\left\{W_{1}(x)-\left(\frac{B(n) x^{\xi}}{\rho-\hat{\mu}}-\frac{c}{\rho}\right)\right\}=0 \quad \text { and } \quad \lim _{x \rightarrow 0} W_{0}(x)=0
$$

where the term $\frac{B(n) x^{\xi}}{\rho-\hat{\mu}}-\frac{c}{\rho}$ indicates the present value of the future expected benefits which the actual user expects to obtain from indefinite use of the resource (Harrison 1985, p. 44). To guarantee the positivity of this term we need to assume $\rho-\hat{\mu}>0$.

From the linearity of the differential equations (7) and (8) and using (13), it is possible to show that the value of the right to use the collective resource for an actual user is given by:

$$
W_{1}(x)=A_{1} x^{-\alpha}+\left(\frac{B(n) x^{\xi}}{\rho-\hat{\mu}}-\frac{c}{\rho}\right) \quad \text { for all } x \in\left(x_{L}, \infty\right)
$$

and for a potential user:

$$
W_{0}(x)=A_{0} x^{+\beta} \quad \text { for all } x \in\left(0, x_{H}\right)
$$

with $-\alpha<0$ and $\beta>1$. Having indicated with $\frac{B(n) x^{\xi}}{\rho-\hat{\mu}}-\frac{c}{\rho}$ the present value of the future expected benefits, the additional terms $A_{1} x^{-\alpha}$ and $A_{0} x^{+\beta}$ indicate 
the value of the option to suspend or activate use of the resource, respectively. It therefore follows that the constants $A_{0}$ and $A_{1}$ must be positive. These constants, together with the thresholds $x_{L}$ and $x_{H}$, are obtained by solving the system (9)-(12).

Due to the non-linearity of the system (9)-(12), it is not possible to obtain a closed solution for $x_{L}$ and $x_{H}$. However, it is possible to obtain some properties of $x_{L}$ and $x_{H}$. The characteristics of the entry thresholds of the potential user and exit thresholds of the actual user can be deduced from the following proposition where the interval is defined within which to find the optimal threshold values (see Appendix).

Proposition: If $c>\rho l$, the threshold for abandonment of use of the resource satisfies the inequality:

$$
B(n) x_{L}^{\xi} \geq \frac{\alpha}{1+\alpha} \frac{\rho-\hat{\mu}}{\rho}(c-\rho l)
$$

The threshold for activation of use of the resource satisfies the following inequality:

$$
B(n) x_{H}^{\xi} \leq \frac{\beta}{\beta-1} \frac{\rho-\hat{\mu}}{\rho}(c+\rho k)
$$

The proposition highlights two bounds, lower and upper, within which to identify the optimal thresholds. A first analysis shows that these limit values are simply the Marshall long-run average costs $(c-\rho l)$ and $(c+\rho k)$ multiplied by a factor, $\frac{\alpha}{1+\alpha} \frac{\rho-\hat{\mu}}{\rho}<1$ and $\frac{\beta}{\beta-1} \frac{\rho-\hat{\mu}}{\rho}>1$ respectively, which accounts for the irreversibility of the decision to abandon or activate the use of the resource.

In this regard, the classic microeconomic approach clearly shows that the potential user should activate use of the resource if the benefit exceeds the long-run average cost, where by long-run average cost we mean the cost $c$ plus the annual interest (annuity) on the investment $\rho k$. In the same way, an active user should consider the expediency of abandoning use of the resource if the benefit drops below the average $\operatorname{costs} c$. However, if there is an explicit cost of abandoning the activity $l$, the user should take account of the interest $\mathrm{s} / \mathrm{he}$ would save by postponing the exit, i.e. $c-\rho l$.

Furthermore, the proposition maintains that if the user has to take a decision under uncertainty and such a decision involves non-recoverable costs both at entry and exit, the static Marshall thresholds are no longer valid. The optimal values can be "considerably" different: for activation, the potential user waits for the benefit to rise well above the long-run average cost before starting to use the resource, and before abandoning it the actual user waits for the benefit to drop well below the average exit cost.

Obviously if $c \leq \rho l$, the trigger value $x_{L}$ is placed equal to zero and the option to abandon loses value, which is equivalent to placing $A_{1}=0$ in (14). Therefore: 
Corollary: If $c \leq \rho l$, the threshold for abandoning use of the resource is equal to $x_{L}=0$, while the threshold for activation becomes:

$$
B(n) x_{H}^{\xi}=\frac{\beta}{\beta-1} \frac{\rho-\hat{\mu}}{\rho}(c+\rho k)
$$

\section{Some comparative statics}

The results obtained in the proposition can be used to assess the effect of changes in the boundary conditions of use of the resource. By the dynamic structure of the model, the simulations were performed essentially for investigating the trend of the entry and exit threshold values. Analysis of the thresholds permits evaluation of the effect of a certain action on the direction and stability of evolution of use of the common property resource.

The following table shows the possible states in use of the resource that can be obtained by comparing the amount of the resource with respect to the thresholds $\left(x_{L}, x_{H}\right)$ and with respect to the extent of the difference between the same, which can be defined as the hysteresis range $\left(\Delta_{H L}=x_{H}-x_{L}\right)$. This difference can be considered a proxy of the stability of the system: the greater the interval $\Delta_{H L}$ the greater the fluctuations in the availability of the resource that do not affect the decisions of the user.

Table 4 - Dynamics of use of the common resource

\begin{tabular}{|c|c|c|}
\hline \multirow{2}{*}{ Resource situation } & \multicolumn{2}{|c|}{ Hysteresis $\left(\Delta_{H L}\right)$} \\
\cline { 2 - 3 } & Low & High \\
\hline$x_{t}<x_{L}$ & Unstable abandonment & Stable abandonment \\
\hline$x_{L}<x_{t}<x_{H}$ & Unstable stagnation & Stable stagnation \\
\hline$x_{H}<x_{t}$ & Unstable use & Stable use \\
\hline
\end{tabular}

Examining the results of comparative statics, the effect of the following factors was taken into consideration:

1. the non-recoverable cost of entry $(k)$ and exit $(l)$;

2. the flow fixed cost $(c)$;

3. the uncertainty $(\sigma)$;

4. the number of rivals $(n)$.

The simulations of the entry cost $(k)$ highlighted that as it increases, the level of hysteresis $\left(\Delta_{H L}\right)$ increases. In other words, the threshold values diverge as the entry cost increases $\left(\frac{d x_{H}}{d k}>0, \frac{d x_{L}}{d k}<0\right)$. The formal demonstration of this result can be found in Dixit and Pindyck (1994, chap.7). In any case, this result is also intuitively justified: the potential user postpones implementation of his decision as the cost increases and, therefore, $x_{H}$ increases. Moreover, 
this trend can also be derived from the classic microeconomic approach. It is also interesting to note that as $k$ increases, $x_{L}$ diminishes and, therefore, the tendency to abandon use of the resource once activated. In fact, as the amount of the resource available is uncertain, there is the possibility that use of the same will become once again expedient in the future. In this case, continuing use, the user can avoid running into the increasing non-recoverable expense $k$. As the cost $k$ increases, the value of the option to abandon increases and therefore the expediency of retaining it increases. The increase in the entry cost $k$ always results in a stabilisation of the current situation: in fact the threshold values that make it expedient to exercise any option (entry or exit) become more remote.

This result allows us to throw light on the effect of possible incentives to the entry of users of common resources. The incentive that involves a reduction in the non-recoverable entry costs causes the thresholds to converge and therefore makes the system more flexible, both at entry and exit.

Similar results are obtained by increasing the exit cost $(l)$. In fact, the threshold values diverge as the exit cost grows $\left(\frac{d x_{H}}{d l}>0, \frac{d x_{L}}{d l}<0\right)$. The explanation, both formal and intuitive, is similar to the previous one: if the exit cost increases, the expediency of continuing use will be strengthened, postponing the recovery costs. Likewise, for the potential user, an increase in the exit cost is a disincentive to activating use of the resource as it means an increase in outlay to be sustained if the resource contracts in the future, making use of it no longer expedient.

The model enabled us to highlight that the existence of non-recoverable costs, both entry and exit, generates the divergence between the entry and exit thresholds. Obviously, if these costs are not present, the decision is perfectly flexible and the threshold values in the benefit converge at the operating cost $\left[\lim _{k, l \rightarrow 0} B(n) x_{H}^{\xi}, B(n) x_{L}^{\xi}=c\right]$. In this case, the threshold value, unique, increases as the flow fixed cost increases $\left(\frac{d x_{L, H}}{d c}>0\right)$. A resource for which the fixed costs associated with operation increase will be more difficult to use and will be abandoned more easily.

The analysis performed so far could have been carried out using traditional economic analysis tools. The model permits a more detailed study of the effect of the uncertainty, however. In this regard it is possible to demonstrate that an increase in the uncertainty relating to the dimension of the future stock of the resource $(\sigma)$ always entails an increase in the hysteresis $\left(\Delta_{H L}\right)$ i.e.: $\frac{d x_{H}}{d \sigma}>$ $0, \frac{d x_{L}}{d \sigma}<0$. In fact, it is easy to demonstrate that $\frac{\partial \beta}{\partial \sigma}<0$, therefore an increase in $\sigma$ increases the multiplication coefficient $\frac{\beta}{\beta-1}$. Likewise, it can be shown that $\frac{\partial \alpha}{\partial \sigma}>0$, so that an increase in $\sigma$ reduces the multiplication coefficient $\frac{\alpha}{1+\alpha}$. The overall effect of an increase in uncertainty is to increase the difference between the optimal threshold values $x_{H}$ and $x_{L}$.

Uncertainty, therefore, amplifies the effect of the non-recoverable entry and exit costs and its modulation can constitute a lever in government of the common property resource. The quantity of information to be circulated and "programming" of the use, by reducing the uncertainty, can reduce the level of hysteresis 
and make the system more flexible at both entry and exit. It should not be forgotten, in fact, that the effect of the uncertainty is to increase the degree of inertia of the user, anchoring him to his present state.

Lastly, the simulations have highlighted that the effect of an increase in the number of users has different effects according to certain boundary assumptions. For example, if the number of users does not alter the growth rate of the resource and therefore the productivity does not drop $\left[\mu^{\prime}(n)=0\right]$ and there is a reduction in the benefit that can be obtained by the individual user due to mutual disturbance [regardless of the rivalry, $B^{\prime}(n)<0$ ], an increase in the number of rivals involves an increase in both threshold values $\left(\frac{d x_{H}}{d n}>0, \frac{d x_{L}}{d n}>0\right)$. This effect is due to the decreasing marginal benefits with respect to the number of users. Assuming the same conditions, therefore, an increase in the number of rivals produces a disincentive to exercise of the entry option in the presence of decreasing benefits. Likewise, for the actual user, the entry of new competitors can be an incentive to exercising the exit option.

If, on the other hand, the number of users does not alter the marginal benefit $\left[B^{\prime}(n)=0\right]$, but reduces the marginal productivity $\left[\mu^{\prime}(n)<0\right]$, an increase in the number of rivals involves a reduction in the threshold values: $\frac{d x_{H}}{d n}<0, \frac{d x_{L}}{d n}<0$. The effect is due to the fact that the increase in $n$ reduces the productivity $(\hat{\mu})$, which causes $\beta$ to increase, therefore leading to a reduction in the multiplication coefficient $\frac{\beta}{\beta-1}$. The opposite effect occurs for the coefficient $\alpha$. In short, if the user is aware that the increase in the number of users affects the growth rate of the resource, and there are no significant negative congestion effects, he will be stimulated to activate use of the resource to avoid future competition over the decreasing resource.

Lastly, in the case in which the increase in competitors simultaneously produces a reduction in the future growth rate of the resource and a congestion effect on the private benefit $\left[B^{\prime}(n)<0\right.$ and $\left.\mu^{\prime}(n)<0\right]$, it is impossible to define a priori the cumulative effect on the entry and exit thresholds. It will depend on the relative amount of the reduction in the growth rate with respect to the congestion effect.

\section{Conclusions}

The government of common property resources is a very topical subject and there is a certain interest in analysis of the institutions that have shown an ability in the past to manage natural resources in a "sustainable" manner. It is fairly difficult to explain the reasons for this success.

Analysis of the institutional and social aspects appears to be essential in order to explain the formation and development of these institutions over time. In the context of this analysis, study of the behaviour of the individual user is important; in fact, achievement of the social objectives of use of the common property resources also depends on his decisions. This study illustrates a model for representing the behaviour of a user of a common and reproducible natural resource. The model was developed from the assumption that the expediency 
of exercising a right to use is comparable to a real option since the uncertainty as regards future benefits and the irreversibility of certain expenses make it expedient to wait before activating or abandoning the use. This approach has involved the development of a model for determination of the value of the right to use and the rules that govern exercise of it. The model was used to verify the behaviour of the user as the boundary conditions varied.

Firstly, the simulations highlighted that the decision of the user to exercise the entry or exit option is taken with respect to two different thresholds and that said thresholds diverge due to the non-recoverable entry and exit costs and the uncertainty with regard to future availability of the resource. The difference between thresholds, hysteresis, significantly influences the flexibility of use of the resource: a high hysteresis produces an increase in inertia of the users who are anchored to their initial condition.

Attention has therefore shifted to factors affecting the degree of hysteresis.

The amount of the non-recoverable entry and exit cost significantly influences the difference between the thresholds, which grows as said costs increase. This result allows us to assess the possibility of tailoring possible incentives to the entry of users of common resources. The incentive, by reducing the nonrecoverable entry costs, causes the thresholds to converge and makes the system more flexible, both at entry and exit. Similar effects are produced by the exit incentive. If there are no non-recoverable entry and exit costs, the threshold value, unique, is determined by the fixed cost per unit of preriod, an increase in which always produces an increase in the threshold.

Uncertainty amplifies the effect of the non-recoverable costs and an increase in uncertainty always involves an increase in hysteresis. Control of uncertainty makes the system more flexible, both at entry and exit, reducing user inertia.

Lastly, the simulations highlighted that the increase in the number of users has fairly ambiguous effects. If there is a considerable congestion effect, additional to the rivalry in use of the resource, but the growth rate of the resource is not affected, the increase in the number of users acts as a deterrent to use, encouraging exits and discouraging entries. If, on the contrary, the increase in the number of users negatively affects the productivity of the resource, but there is no congestion effect, the user is stimulated to use the resource immediately in order to avoid future competition. If a significant congestion among users and reduction of the productive capacity of the resource occur simultaneously, it is not possible to identify a univocal effect. The final result is linked to the relative extent of the impact of the increase in congestion and reduction in productivity of the resource on the benefit of the user. 
The proposition in the text can be proved by substituting equations (14) and (15) in (9)-(12) and obtaining the following system of four equations:

$$
\begin{aligned}
& A_{1} x_{L}^{-\alpha}+\left(\frac{B(n) x_{L}^{\xi}}{\rho-\hat{\mu}}-\frac{c}{\rho}\right)=A_{0} x_{L}^{+\beta}-l \\
& -A_{1} \alpha x_{L}^{-\alpha-1}+\frac{B(n) \xi x_{L}^{\xi-1}}{\rho-\hat{\mu}}=A_{0} \beta x_{L}^{\beta-1} \\
& A_{1} x_{H}^{-\alpha}+\left(\frac{B(n) x_{H}^{\xi}}{\rho-\hat{\mu}}-\frac{c}{\rho}\right)=A_{0} x_{H}^{+\beta}+k \\
& -A_{1} \alpha x_{H}^{-\alpha-1}+\frac{B(n) \xi x_{L}^{\xi-1}}{\rho-\hat{\mu}}=A_{0} \beta x_{H}^{\beta-1}
\end{aligned}
$$

Since the above system is linear in $A_{0}$ and $A_{1}$, by substituting (16) in (17) we get:

$$
\begin{aligned}
& A_{1} x_{L}^{-\alpha}=\left[\frac{1-\beta}{\alpha+\beta}\left(\frac{1}{\rho-\hat{\mu}} B(n) x_{L}^{\xi}\right)+\frac{\beta}{\alpha+\beta}\left(\frac{c}{\rho}-l\right)\right] \\
& A_{0} x_{L}^{+\beta}=\left[\frac{1+\alpha}{\alpha+\beta}\left(\frac{1}{\rho-\mu} B(n) x_{L}^{\xi}\right)-\frac{\alpha}{\alpha+\beta}\left(\frac{c}{\rho}-l\right)\right]
\end{aligned}
$$

The equation (20) indicates the value of the option that an actual user has to abandon use of the resource in the future, assessed at the exit threshold $x_{L}$. For this value to be positive, it is sufficient for the right-hand side of (20) to be positive, i.e. it must be:

$$
B(n) x_{L}^{\xi} \leq \frac{\beta}{\beta-1} \frac{\rho-\hat{\mu}}{\rho}(c-\rho l)
$$

Symmetrically, the equation (21) refers to the option value to become an active user, calculated at the exit threshold $x_{L}$. Here again, for this value to be positive, the following is necessary:

$$
B(n) x_{L}^{\xi} \geq \frac{\alpha}{1+\alpha} \frac{\rho-\hat{\mu}}{\rho}(c-\rho l)
$$

Since $\beta>1$ and $\alpha>0$ we have $\frac{\beta}{\beta-1}>1>\frac{\alpha}{1+\alpha}>0$, and with $\rho>\hat{\mu}$, the inequalities (22) and (23) are both positive or both negative according to the sign of the term $(c-\rho l)$. In this specific case:

$$
x_{L} \leq 0 \quad \text { if and only if } c \leq \rho l
$$




$$
x_{L} \geq 0 \quad \text { if and only if } c \geq \rho l
$$

Reasoning in the same way, it is possible to obtain an interval for the activation threshold $x_{H}$, which is always positive and greater than $x_{L}$. Considering the last two equations, (18) and (19), and substituting (18) in (19) we get:

$$
\begin{aligned}
& A_{1} x_{H}^{-\alpha}=\left[\frac{1-\beta}{\alpha+\beta}\left(\frac{1}{\rho-\hat{\mu}} B(n) x_{H}^{\xi}\right)+\frac{\beta}{\alpha+\beta}\left(\frac{c}{\rho}+k\right)\right] \\
& A_{0} x_{H}^{+\beta}=\left[\frac{1+\alpha}{\alpha+\beta}\left(\frac{1}{\rho-\mu} B(n) x_{H}^{\xi}\right)-\frac{\alpha}{\alpha+\beta}\left(\frac{c}{\rho}+k\right)\right]
\end{aligned}
$$

For the value of the option to be positive, it is sufficient for the right-hand side to be positive, i.e.:

$$
B(n) x_{H}^{\xi} \leq \frac{\beta}{\beta-1} \frac{\rho-\hat{\mu}}{\rho}(c+\rho k)
$$

and:

$$
B(n) x_{H}^{\xi} \geq \frac{\alpha}{1+\alpha} \frac{\rho-\hat{\mu}}{\rho}(c+\rho k)
$$

Putting together the (22), (23), (26) and (27) we obtain the admissibility range for $x_{L}$ and $x_{H}$ given in the text. 


\section{References}

[1] Acerbo, G. (1924), Il riordinamento degli usi civici del Regno, Relazione presentata alla Camera dei Deputati, cit. in G. Medici (1972) Principi di estimo, Edizioni Calderini, Bologna.

[2] Arnason, R. (1990), "Minimum Information Management in Fisheries", Canadian Journal of Economics, 23, pp. 630-653.

[3] Baumol, W.J. - Oates W.E. (1988), The theory of environmental policy, Cambridge University Press, Cambridge.

[4] Brosio, G. (1986), Economia e finanza pubblica, NIS, Roma.

[5] Conrad, J.M. (1999), Resource Economics, Cambridge University Press, Cambridge.

[6] Cox, D.R. - H.D. Miller, (1965), The Theory of Stochastic Process, Chapman and Hall, London.

[7] Dixit, A. (1989), "Entry and Exit Decisions under Uncertainty", Journal of Political Economy, 97(3), pp. 620-638.

[8] Dixit, A. - Pindyck R.S. (1994), Investment under Uncertainty, Princeton University Press, Princeton.

[9] Edwards, S. (1998), Istitutional Structures and Regulation on Community Owned Forests in the Province of Trento, Italy, Jobst H., Merlo M., Venzi L., Institutional Aspects of Managerial Economics and Accounting in Forestry, IUFRO pp.215-240.

[10] Forni, G. (1972), "Società e agricoltura preistoriche nelle regioni montane della padania", Rivista di storia dell'agricoltura, 12(1-2), pp. 27-32.

[11] Franceschetti, G. (1999), "Verso l'integrazione tra politica agricola e politica ambientale in aree montane: alcuni strumenti operativi", Rivista di Politica Agraria, 5, pp. 45-55.

[12] Freeman III, A.M. (1984), "The Signe and Size of Option Value", Land Economics, 60(1), pp. 1-13.

[13] Hardin, G. (1968), "The Tragedy of the Commons", Science, 162, pp. 12431248.

[14] Harrison J.M. (1985), Brownian Motions and Stochastic Flow Systems, Wiley, New York.

[15] Howarth, B.H. (1997), "Defining Sustainability: An Overwiev", in B.H. Howarth (ed.) Special Isuue: Defining Sustainability, Land Economics, 73(4), pp. $445-447$. 
[16] Merlo, M. (1995), "Common Property Forest Management in Northern Italy: an Historical and Socio-economic Profile", Unasylva, 180(46), pp. $58-63$.

[17] Moretto, M. (1996), "A Note on Entry-Exit Timing with Firm-Specific Shocks", Giornale degli Economisti e Annali di Economia, 55(1), pp. 7595.

[18] Moretto, M. - Rosato, P. (2000), "The Value of Licenses for Recreational Resources Use", FEEM Note di Lavoro, n. 64, Milano.

[19] Ostrom, E. (1996), "Nè mercato nè stato nella gestione delle risorse collettive", La Questione Agraria, 64, pp. 7-39.

[20] Ostrom, E. (1999), "How Some Communities Have Avoided the Tragedy of the Commons", Quaderni di Ricerca del Centro di Documentazione sui Demani Civici e le Proprietà Collettive, Università di Trento, pp. 55.

[21] Ostrom, E. - Gardner, R. - Walker, J. (1994), Rules, Games and CommonPool Resources, The University of Michigan Press, Ann Arbor.

[22] Pearce, D.W. - Turner R.K. (1990), Economics of Natural Resources an the Environment, John Hopkins University Press, Baltimore.

[23] Pitteri M. (1984), Segar le acque, Comune di Quinto di Treviso, Treviso,.

[24] Sereni, E. (1955), Comunità rurali nell'Italia antica, Rinascita Edizioni, Roma.

[25] Tirole, J. (1988), The Theory of Industrial Organization, MIT Press, Cambridge MA. 


\title{
NOTE DI LAVORO DELLA FONDAZIONE ENI ENRICO MATTEI \\ Fondazione Eni Enrico Mattei Working Papers Series \\ Our working papers are available on the Internet at the following addresses: \\ Server WWW: WWW.FEEM.IT \\ Anonymous FTP: FTP.FEEM.IT \\ To order any of these papers, please fill out the form at the end of the list.
}

\begin{abstract}
SUST $\quad 1.2001 \quad$ Inge MAYERES and Stef PROOST: Should Diesel Cars in Europe be Discouraged?
SUST 2.2001 Paola DORIA and Davide PETTENELLA: The Decision Making Process in Defining and Protecting Critical Natural Capital

CLIM $3.2001 \quad$ Alberto PENCH: Green Tax Reforms in a Computable General Equilibrium Model for Italy

CLIM 4.2001 Maurizio BUSSOLO and Dino PINELLI: Green Taxes: Environment, Employment and Growth

CLIM 5.2001 Marco STAMPINI: Tax Reforms and Environmental Policies for Italy

ETA $\quad 6.2001$

CLIM $\quad 7.2001$

Walid OUESLATI: Environmental Fiscal Policy in an Endogenous Growth Model with Human Capital

Umberto CIORBA, Alessandro LANZA and Francesco PAULI: Kyoto Commitment and Emission Trading: a European Union Perspective

MGMT 8.2001 Brian SLACK (xlv): Globalisation in Maritime Transportation: Competition, uncertainty and implications for port development strategy

VOL 9.2001 Giulia PESARO: Environmental Voluntary Agreements: A New Model of Co-operation Between Public and Economic Actors

VOL 10.2001 Cathrine HAGEM: Climate Policy, Asymmetric Information and Firm Survival

ETA 11.2001 Sergio CURRARINI and Marco MARINI: A Sequential Approach to the Characteristic Function and the Core in Games with Externalities

ETA 12.2001 Gaetano BLOISE, Sergio CURRARINI and Nicholas KIKIDIS: Inflation and Welfare in an OLG Economy with a Privately Provided Public Good

KNOW 13.2001 Paolo SURICO: Globalisation and Trade: A “New Economic Geography" Perspective

ETA $14.2001 \quad$ Valentina BOSETTI and Vincenzina MESSINA: Quasi Option Value and Irreversible Choices

CLIM 15.2001 Guy ENGELEN (xlii): Desertification and Land Degradation in Mediterranean Areas: from Science to Integrated Policy Making

SUST 16.2001 Julie Catherine SORS: Measuring Progress Towards Sustainable Development in Venice: A Comparative Assessment of Methods and Approaches

SUST 17.2001 Julie Catherine SORS: Public Participation in Local Agenda 21: A Review of Traditional and Innovative $\underline{\text { Tools }}$

CLIM 18.2001 Johan ALBRECHT and Niko GOBBIN: Schumpeter and the Rise of Modern Environmentalism

VOL 19.2001 Rinaldo BRAU, Carlo CARRARO and Giulio GOLFETTO (xliii): Participation Incentives and the Design of Voluntary Agreements

ETA $20.2001 \quad$ Paola ROTA: Dynamic Labour Demand with Lumpy and Kinked Adjustment Costs

ETA $21.2001 \quad$ Paola ROTA: Empirical Representation of Firms' Employment Decisions by an (S,s) Rule

ETA 22.2001 Paola ROTA: What Do We Gain by Being Discrete? An Introduction to the Econometrics of Discrete Decision Processes

PRIV 23.2001 Stefano BOSI, Guillaume GIRMANS and Michel GUILLARD: Optimal Privatisation Design and Financial Markets

KNOW 24.2001 Giorgio BRUNELLO, Claudio LUPI, Patrizia ORDINE, and Maria Luisa PARISI: Beyond National Institutions: Labour Taxes and Regional Unemployment in Italy

ETA 25.2001 Klaus CONRAD: Locational Competition under Environmental Regulation when Input Prices and Productivity Differ

PRIV 26.2001 Bernardo BORTOLOTTI, Juliet D'SOUZA, Marcella FANTINI and William L. MEGGINSON: Sources of Performance Improvement in Privatised Firms: A Clinical Study of the Global Telecommunications Industry

CLIM 27.2001

Frédéric BROCHIER and Emiliano RAMIERI: Climate Change Impacts on the Mediterranean Coastal $\underline{\text { Zones }}$

ETA 28.2001 Nunzio CAPPUCCIO and Michele MORETTO: Comments on the Investment-Uncertainty Relationship in a Real Option Model

KNOW 29.2001 Giorgio BRUNELLO: Absolute Risk Aversion and the Returns to Education

CLIM 30.2001 ZhongXiang ZHANG: Meeting the Kyoto Targets: The Importance of Developing Country Participation

ETA 31.2001 Jonathan D. KAPLAN, Richard E. HOWITT and Y. Hossein FARZIN: An Information-Theoretical Analysis of Budget-Constrained Nonpoint Source Pollution Control

MGMT $32.2001 \quad$ Roberta SALOMONE and Giulia GALLUCCIO: Environmental Issues and Financial Reporting Trends
\end{abstract}


Coalition

Theory

Network

ETA

34.2001

NRM

35.2001

KNOW $\quad 36.2001$

PRIV

CLIM

37.2001

38.2001

PRIV

39.2001

KNOW $\quad 40.2001$

Coalition 41.2001

Theory

Network

Coalition 42.2001

Theory

Network

Coalition 43.2001

Theory

Network

Coalition 44.2001

Theory

Network

NRM

45.2001

NRM

46.2001

NRM

47.2001

CLIM

48.2001

CLIM $\quad 49.2001$

SUST

SUST

50.2001

51.2001

SUST

SUST

52.2001

53.2001

SUST

54.2001

SUST

55.2001

SUST

SUST

SUST

SUST

ETA

CLIM

PRIV

CLIM
Shlomo WEBER and Hans WIESMETH: From Autarky to Free Trade: The Impact on Environment

Margarita GENIUS and Elisabetta STRAZZERA: Model Selection and Tests for Non Nested Contingent Valuation Models: An Assessment of Methods

Carlo GIUPPONI: The Substitution of Hazardous Molecules in Production Processes: The Atrazine Case Study in Italian Agriculture

Raffaele PACI and Francesco PIGLIARU: Technological Diffusion, Spatial Spillovers and Regional Convergence in Europe

Bernardo BORTOLOTTI: Privatisation, Large Shareholders, and Sequential Auctions of Shares

Barbara BUCHNER: What Really Happened in The Hague? Report on the COP6, Part I, 13-25 November 2000, The Hague, The Netherlands

Giacomo CALZOLARI and Carlo SCARPA: Regulation at Home, Competition Abroad: A Theoretical Framework

Giorgio BRUNELLO: On the Complementarity between Education and Training in Europe

Alain DESDOIGTS and Fabien MOIZEAU (xlvi): Multiple Politico-Economic Regimes, Inequality and Growth

Parkash CHANDER and Henry TULKENS (xlvi): Limits to Climate Change

Michael FINUS and Bianca RUNDSHAGEN (xlvi): Endogenous Coalition Formation in Global Pollution Control

Wietze LISE, Richard S.J. TOL and Bob van der ZWAAN (xlvi): Negotiating Climate Change as a Social Situation

Mohamad R. KHAWLIE (xlvii): The Impacts of Climate Change on Water Resources of LebanonEastern Mediterranean

Mutasem EL-FADEL and E. BOU-ZEID (xlvii): Climate Change and Water Resources in the Middle East: Vulnerability, Socio-Economic Impacts and Adaptation

Eva IGLESIAS, Alberto GARRIDO and Almudena GOMEZ (xlvii): An Economic Drought Management

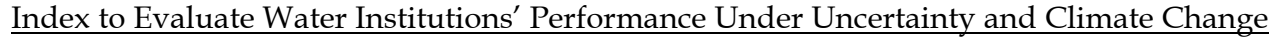

Wietze LISE and Richard S.J. TOL (xlvii): Impact of Climate on Tourist Demand

Francesco BOSELLO, Barbara BUCHNER, Carlo CARRARO and Davide RAGGI: Can Equity Enhance Efficiency? Lessons from the Kyoto Protocol

Roberto ROSON (xlviii): Carbon Leakage in a Small Open Economy with Capital Mobility

Edwin WOERDMAN (xlviii): Developing a European Carbon Trading Market: Will Permit Allocation Distort Competition and Lead to State Aid?

Richard N. COOPER (xlviii): The Kyoto Protocol: A Flawed Concept

Kari KANGAS (xlviii): Trade Liberalisation, Changing Forest Management and Roundwood Trade in Europe

Xueqin ZHU and Ekko VAN IERLAND (xlviii): Effects of the Enlargement of EU on Trade and the Environment

Foreign Direct Investment

56.2001 Savas ALPAY (xlviii): Can Environmental Regulations be Compatible with Higher International Competitiveness? Some New Theoretical Insights

57.2001 Roldan MURADIAN, Martin O'CONNOR, Joan MARTINEZ-ALER (xlviii): Embodied Pollution in Trade: Estimating the "Environmental Load Displacement" of Industrialised Countries

58.2001 Matthew R. AUER and Rafael REUVENY (xlviii): Foreign Aid and Direct Investment: Key Players in the Environmental Restoration of Central and Eastern Europe

59.2001 Onno J. KUIK and Frans H. OOSTERHUIS (xlviii): Lessons from the Southern Enlargement of the EU for the Environmental Dimensions of Eastern Enlargement, in particular for Poland

60.2001 Carlo CARRARO, Alessandra POME and Domenico SINISCALCO (xlix): Science vs. Profit in Research: Lessons from the Human Genome Project

61.2001 Efrem CASTELNUOVO, Michele MORETTO and Sergio VERGALLI: Global Warming, Uncertainty and Endogenous Technical Change: Implications for Kyoto

62.2001 Gian Luigi ALBANO, Fabrizio GERMANO and Stefano LOVO: On Some Collusive and Signaling Equilibria in Ascending Auctions for Multiple Objects

63.2001 Elbert DIJKGRAAF and Herman R.J. VOLLEBERGH: $\underline{\text { A Note on Testing for Environmental Kuznets }}$ Curves with Panel Data 
CLIM 64.2001 Paolo BUONANNO, Carlo CARRARO and Marzio GALEOTTI: Endogenous Induced Technical Change and the Costs of Kyoto

CLIM 65.2001 Guido CAZZAVILLAN and Ignazio MUSU (1): Transitional Dynamics and Uniqueness of the BalancedGrowth Path in a Simple Model of Endogenous Growth with an Environmental Asset

CLIM 66.2001 Giovanni BAIOCCHI and Salvatore DI FALCO (1): Investigating the Shape of the EKC: A Nonparametric Approach

CLIM 67.2001 Marzio GALEOTTI, Alessandro LANZA and Francesco PAULI (1): Desperately Seeking (Environmental) Kuznets: A New Look at the Evidence

CLIM 68.2001 Alexey VIKHLYAEV (xlviii): The Use of Trade Measures for Environmental Purposes - Globally and in the EU Context

NRM 69.2001 Gary D. LIBECAP and Zeynep K. HANSEN (li): U.S. Land Policy, Property Rights, and the Dust Bowl of the 1930s

NRM 70.2001 Lee J. ALSTON, Gary D. LIBECAP and Bernardo MUELLER (li): Land Reform Policies, The Sources of Violent Conflict and Implications for Deforestation in the Brazilian Amazon

CLIM 71.2001 Claudia KEMFERT: Economy-Energy-Climate Interaction - The Model WIAGEM -

SUST 72.2001 Paulo A.L.D. NUNES and Yohanes E. RIYANTO: Policy Instruments for Creating Markets for Bodiversity: Certification and Ecolabeling

SUST 73.2001 Paulo A.L.D. NUNES and Erik SCHOKKAERT (lii): Warm Glow and Embedding in Contingent Valuation

SUST 74.2001 Paulo A.L.D. NUNES, Jeroen C.J.M. van den BERGH and Peter NIJKAMP (lii): Ecological-Economic Analysis and Valuation of Biodiversity

VOL 75.2001 Johan EYCKMANS and Henry TULKENS (li): Simulating Coalitionally Stable Burden Sharing Agreements for the Climate Change Problem

PRIV 76.2001 Axel GAUTIER and Florian HEIDER: What Do Internal Capital Markets Do? Redistribution vs. Incentives

PRIV 77.2001 Bernardo BORTOLOTTI, Marcella FANTINI and Domenico SINISCALCO: Privatisation around the World: New Evidence from Panel Data

ETA 78.2001 Toke S. AIDT and Jayasri DUTTA (li): Transitional Politics. Emerging Incentive-based Instruments in Environmental Regulation

ETA 79.2001 Alberto PETRUCCI: Consumption Taxation and Endogenous Growth in a Model with New Generations

ETA 80.2001 Pierre LASSERRE and Antoine SOUBEYRAN (li): A Ricardian Model of the Tragedy of the Commons

ETA 81.2001 Pierre COURTOIS, Jean Christophe PÉREAU and Tarik TAZDAÏT: An Evolutionary Approach to the Climate Change Negotiation Game

NRM 82.2001 Christophe BONTEMPS, Stéphane COUTURE and Pascal FAVARD: Is the Irrigation Water Demand Really Convex?

NRM 83.2001 Unai PASCUAL and Edward BARBIER: A Model of Optimal Labour and Soil Use with Shifting Cultivation

CLIM 84.2001 Jesper JENSEN and Martin Hvidt THELLE: What are the Gains from a Multi-Gas Strategy?

CLIM 85.2001 Maurizio MICHELINI (liii): IPCC “Summary for Policymakers" in TAR. Do its results give a scientific support always adequate to the urgencies of Kyoto negotiations?

CLIM 86.2001 Claudia KEMFERT (liii): Economic Impact Assessment of Alternative Climate Policy Strategies

CLIM 87.2001 Cesare DOSI and Michele MORETTO: Global Warming and Financial Umbrellas

ETA 88.2001 Elena BONTEMPI, Alessandra DEL BOCA, Alessandra FRANZOSI, Marzio GALEOTTI and Paola ROTA: Capital Heterogeneity: Does it Matter? Fundamental Q and Investment on a Panel of Italian Firms

ETA 89.2001 Efrem CASTELNUOVO and Paolo SURICO: Model Uncertainty, Optimal Monetary Policy and the Preferences of the Fed

CLIM 90.2001 Umberto CIORBA, Alessandro LANZA and Francesco PAULI: Kyoto Protocol and Emission Trading: Does the US Make a Difference?

CLIM 91.2001 ZhongXiang ZHANG and Lucas ASSUNCAO: Domestic Climate Policies and the WTO

SUST 92.2001 Anna ALBERINI, Alan KRUPNICK, Maureen CROPPER, Nathalie SIMON and Joseph COOK (lii): The Willingness to Pay for Mortality Risk Reductions: A Comparison of the United States and Canada

SUST 93.2001 Riccardo SCARPA, Guy D. GARROD and Kenneth G. WILLIS (lii): Valuing Local Public Goods with Advanced Stated Preference Models: Traffic Calming Schemes in Northern England

CLIM 94.2001 Ming CHEN and Larry KARP: Environmental Indices for the Chinese Grain Sector

CLIM 95.2001 Larry KARP and Jiangfeng ZHANG: Controlling a Stock Pollutant with Endogenous Investment and Asymmetric Information

ETA $96.2001 \quad$ Michele MORETTO and Gianpaolo ROSSINI: On the Opportunity Cost of Nontradable Stock Options

SUST 97.2001 Elisabetta STRAZZERA, Margarita GENIUS, Riccardo SCARPA and George HUTCHINSON: The Effect of Protest Votes on the Estimates of Willingness to Pay for Use Values of Recreational Sites

NRM 98.2001 Frédéric BROCHIER, Carlo GIUPPONI and Alberto LONGO: Integrated Coastal Zone Management in the Venice Area - Perspectives of Development for the Rural Island of Sant'Erasmo 
NRM 99.2001 Frédéric BROCHIER, Carlo GIUPPONI and Julie SORS: Integrated Coastal Management in the Venice Area - Potentials of the Integrated Participatory Management Approach

NRM 100.2001 Frédéric BROCHIER and Carlo GIUPPONI: Integrated Coastal Zone Management in the Venice Area A Methodological Framework

PRIV 101.2001 Enrico C. PEROTTI and Luc LAEVEN: Confidence Building in Emerging Stock Markets

CLIM 102.2001 Barbara BUCHNER, Carlo CARRARO and Igor CERSOSIMO: On the Consequences of the U.S. Withdrawal from the Kyoto/Bonn Protocol

SUST 103.2001 Riccardo SCARPA, Adam DRUCKER, Simon ANDERSON, Nancy FERRAES-EHUAN, Veronica GOMEZ, Carlos R. RISOPATRON and Olga RUBIO-LEONEL: Valuing Animal Genetic Resources in Peasant Economies: The Case of the Box Keken Creole Pig in Yucatan

SUST 104.2001 R. SCARPA, P. KRISTJANSON, A. DRUCKER, M. RADENY, E.S.K. RUTO, and J.E.O. REGE: Valuing Indigenous Cattle Breeds in Kenya: An Empirical Comparison of Stated and Revealed Preference Value Estimates

SUST $\quad 105.2001$ Clemens B.A. WOLLNY: The Need to Conserve Farm Animal Genetic Resources Through CommunityBased Management in Africa: Should Policy Makers be Concerned?

SUST 106.2001 J.T. KARUGIA, O.A. MWAI, R. KAITHO, Adam G. DRUCKER, C.B.A. WOLLNY and J.E.O. REGE: Economic Analysis of Crossbreeding Programmes in Sub-Saharan Africa: A Conceptual Framework and Kenyan Case Study

SUST 107.2001 W. AYALEW, J.M. KING, E. BRUNS and B. RISCHKOWSKY: Economic Evaluation of Smallholder Subsistence Livestock Production: Lessons from an Ethiopian Goat Development Program

SUST 108.2001 Gianni CICIA, Elisabetta D'ERCOLE and Davide MARINO: Valuing Farm Animal Genetic Resources by Means of Contingent Valuation and a Bio-Economic Model: The Case of the Pentro Horse

SUST $\quad 109.2001$ Clem TISDELL: Socioeconomic Causes of Loss of Animal Genetic Diversity: Analysis and Assessment

SUST $\quad 110.2001$ M.A. JABBAR and M.L. DIEDHOU: Does Breed Matter to Cattle Farmers and Buyers? Evidence from West Africa

SUST 1.2002 K. TANO, M.D. FAMINOW, M. KAMUANGA and B. SWALLOW: Using Conjoint Analysis to Estimate Farmers' Preferences for Cattle Traits in West Africa

ETA 2.2002 Efrem CASTELNUOVO and Paolo SURICO: What Does Monetary Policy Reveal about Central Bank's Preferences?

WAT $\quad 3.2002$ Duncan KNOWLER and Edward BARBIER: The Economics of a "Mixed Blessing" Effect: A Case Study of the Black Sea

CLIM 4.2002 Andreas LÖSCHEL: Technological Change in Economic Models of Environmental Policy: A Survey

VOL $\quad 5.2002$ Carlo CARRARO and Carmen MARCHIORI: Stable Coalitions

CLIM 6.2002 Marzio GALEOTTI, Alessandro LANZA and Matteo MANERA: Rockets and Feathers Revisited: An International Comparison on European Gasoline Markets

ETA 7.2002 Effrosyni DIAMANTOUDI and Eftichios S. SARTZETAKIS: Stable International Environmental Agreements: An Analytical Approach

KNOW 8.2002 Alain DESDOIGTS: Neoclassical Convergence Versus Technological Catch-up: A Contribution for $\underline{\text { Reaching a Consensus }}$

NRM 9.2002 Giuseppe DI VITA: Renewable Resources and Waste Recycling

KNOW 10.2002 Giorgio BRUNELLO: Is Training More Frequent when Wage Compression is Higher? Evidence from 11 European Countries

ETA 11.2002 Mordecai KURZ, Hehui JIN and Maurizio MOTOLESE: Endogenous Fluctuations and the Role of Monetary Policy

KNOW 12.2002 Reyer GERLAGH and Marjan W. HOFKES: Escaping Lock-in: The Scope for a Transition towards Sustainable Growth?

NRM 13.2002 Michele MORETTO and Paolo ROSATO: The Use of Common Property Resources: A Dynamic Model 
(xlii) This paper was presented at the International Workshop on "Climate Change and Mediterranean Coastal Systems: Regional Scenarios and Vulnerability Assessment" organised by the Fondazione Eni Enrico Mattei in co-operation with the Istituto Veneto di Scienze, Lettere ed Arti, Venice, December 9-10, 1999.

(xliii)This paper was presented at the International Workshop on "Voluntary Approaches, Competition and Competitiveness" organised by the Fondazione Eni Enrico Mattei within the research activities of the CAVA Network, Milan, May 25-26,2000.

(xliv) This paper was presented at the International Workshop on "Green National Accounting in Europe: Comparison of Methods and Experiences" organised by the Fondazione Eni Enrico Mattei within the Concerted Action of Environmental Valuation in Europe (EVE), Milan, March 4-7, 2000

(xlv) This paper was presented at the International Workshop on "New Ports and Urban and Regional Development. The Dynamics of Sustainability" organised by the Fondazione Eni Enrico Mattei, Venice, May 5-6, 2000.

(xlvi) This paper was presented at the Sixth Meeting of the Coalition Theory Network organised by the Fondazione Eni Enrico Mattei and the CORE, Université Catholique de Louvain, Louvain-la-Neuve, Belgium, January 26-27, 2001

(xlvii) This paper was presented at the RICAMARE Workshop "Socioeconomic Assessments of Climate Change in the Mediterranean: Impact, Adaptation and Mitigation Co-benefits", organised by the Fondazione Eni Enrico Mattei, Milan, February 9-10, 2001 (xlviii) This paper was presented at the International Workshop "Trade and the Environment in the Perspective of the EU Enlargement ", organised by the Fondazione Eni Enrico Mattei, Milan, May 17-18, 2001

(xlix) This paper was presented at the International Conference "Knowledge as an Economic Good", organised by Fondazione Eni Enrico Mattei and The Beijer International Institute of Environmental Economics, Palermo, April 20-21, 2001

(1) This paper was presented at the Workshop "Growth, Environmental Policies and + Sustainability" organised by the Fondazione Eni Enrico Mattei, Venice, June 1, 2001

(li) This paper was presented at the Fourth Toulouse Conference on Environment and Resource Economics on "Property Rights, Institutions and Management of Environmental and Natural Resources", organised by Fondazione Eni Enrico Mattei, IDEI and INRA and sponsored by MATE, Toulouse, May 3-4, 2001

(lii) This paper was presented at the International Conference on "Economic Valuation of Environmental Goods", organised by Fondazione Eni Enrico Mattei in cooperation with CORILA, Venice, May 11, 2001

(liii) This paper was circulated at the International Conference on "Climate Policy - Do We Need a New Approach?", jointly organised by Fondazione Eni Enrico Mattei, Stanford University and Venice International University, Isola di San Servolo, Venice, September 6-8, 2001 


\section{SERIES}

MGMT Corporate Sustainable Management (Editor: Andrea Marsanich)

CLIM Climate Change Modelling and Policy (Editor: Marzio Galeotti )

PRIV Privatisation, Antitrust, Regulation (Editor: Bernardo Bortolotti)

KNOW Knowledge, Technology, Human Capital (Editor: Dino Pinelli)

NRM Natural Resources Management (Editor: Carlo Giupponi)

SUST Sustainability Indicators and Environmental Evaluation (Editor: Marialuisa Tamborra)

VOL Voluntary and International Agreements (Editor: Carlo Carraro)

ETA Economic Theory and Applications (Editor: Carlo Carraro)

\section{SERIES}

MGMT Corporate Sustainable Management (Editor: Andrea Marsanich)

CLIM Climate Change Modelling and Policy (Editor: Marzio Galeotti )

PRIV Privatisation, Antitrust, Regulation (Editor: Bernardo Bortolotti)

KNOW Knowledge, Technology, Human Capital (Editor: Dino Pinelli)

NRM Natural Resources Management (Editor: Carlo Giupponi)

SUST Sustainability Indicators and Environmental Evaluation (Editor: Marialuisa Tamborra)

VOL Voluntary and International Agreements (Editor: Carlo Carraro)

ETA Economic Theory and Applications (Editor: Carlo Carraro) 
